\title{
CORNEAL GRAFTING-REPARATIVE AND OPTICAL
}

BY

Lieut.-Col. R. E. Wright, C.I.E., I.M.S.

SUPERINTENDENT, GOVERNMENT OPHTHALMIC HOSPITAL, MADRAS

IN corneal grafting the ideal end is a clear transplant of ample dimensions. Various methods have been devised and tried from time to time in ophthalmological centres throughout the world with limited success, although Elschnig has had brilliant practical results in man in a number of cases. Recently Tudor Thomas, working at first with rabbits, and adopting a modification of the circular graft technique, employed it successfully in man in a few cases. I have been interested in corneal grafting for a considerable time, more particularly in larger grafts for which experimental instruments had been designed locally, but a finished armamentarium was not to hand, and the matter was out of mind, when a case of intermittent corneal fistula came before me for treatment. Corneal ulcer with Descemetocele and fistula is sometimes most rapidly and successfully treated by a thin graft on a suitably prepared bed, e.g., a conjunctival flap, or a Thiersch skin graft used with a contact glass or paraffin shell as described by me elsewhere; but on this occasion it occurred to me that a corneal graft, if successful, might eventually give a better optical result. The base of the Descemetocele was about $1.5 \mathrm{~mm}$. in diameter, and the epithelialized sides of the ulcer shelved gradually up all round to corneal surface level. The detail of the grafting was as follows :-

The graft was taken from the cornea of a blind glaucomatous eye. An ordinary $2 \mathrm{~mm}$. sclero-corneal trephine blade was first used to demarcate a disc to a uniform depth of about one-third the thickness of the cornea, then sloped to about $45^{\circ}$ and rotated so as to cut through at one point. With a small Graefe's knife the disc was cut out, its edge of such a bevel that the endothelial aspect of the disc was distinctly less than $2 \mathrm{~mm}$. It was transferred with due precautions as regards traumatism to a watch glass of olive oil and left there during the short time it took to prepare its bed in the fistulous eye. A $2 \mathrm{~mm}$. trephine blade was employed to demarcate a circular cut around the healing edge of the ulcer and $1.5 \mathrm{~mm}$. blade used to cut through at the base of the Descemetocele. Between these two circular incisions a bevelled edge was carefully cut with fine scissors. The graft was transferred from the watch glass with a smooth spatula. The retaining sutures, loosely placed in position beforehand, were then tightened over the graft. They were planned after the manner of Tudor Thomas. The terminal exits of the bites of these sutures in the cornea were 
close to the corneo-scleral junction. The thread used was fine silk sterilized in wax; the needles, Barraquer's fully curved; eyed, $7 \mathrm{~mm}$. point to eye. Liquid paraffin with atropine was instilled into the eye, and both eyes covered with vaseline lint and bandaged. On the fourth day the eye was examined. It was obvious that the graft had taken, the chamber had formed, and the epithelium was continuous over the junction. The relevant case notes are given on page 344. As an optical achievement the operation was a failure, but as a reparative procedure a success.

A second case illustrates three important features in connection with corneal grafting :-

1. Anterior synechiae are not necessarily a contraindication to operation.

2. Large circular grafts may be used with as great ease as small ones, and with as good a chance of a "take."

3. An eye blind of glaucoma is capable of furnishing a graft. (This is important in India where such material is plentiful.)

The patient was a young man admitted on April 1, 1934, practically blind with corneal leucomata, the result of congenital syphilis. His vision in each eye was hand movements close to face; he could not get about alone. The corneal opacities were dense, except at the extreme periphery. With the corneal microscope and corneo-scleral illumination it was possible to make out that the right anterior chamber was of about normal depth, the pupil round and active, while the left was irregularly shallowed on account of anterior synechiae. On this occasion it was determined to use larger trephines locally obtained of 3 to $9 \mathrm{~mm}$. diameter. The right eye was first dealt with. The graft was taken from a patient whose eye was blind of glaucoma. It was so cut that one edge impinged towards the limbus on the zone of vascular arcades for reasons which are opposed in theory to those of certain other workers. The graft was taken in situ from an eye prepared for enucleation; this was carried out by another operator subsequent to the removal of the disc. A $5 \mathrm{~mm}$. trephine blade was used to a uniform depth of $1 \mathrm{~mm}$. and then the trephine tilted so as to cut through on the bevel at one point. The disc was removed with knife and scissors maintaining a fairly steep bevel, so that the endothelial diameter of the disc was slightly less than the surface diameter. The disc was placed in olive oil. The trephine hole in the leucomatous eye was placed in the centre of the cornea. It was fashioned in the same way with a $4 \mathrm{~mm}$. trephine, the sutures being loosely placed beforehand. In this case the graft was definitely bigger than the hole, contrary to Tudor Thomas' technique, but in conformity with the general principles of plastic work. The stitches were pulled moderately tight and the eye dressed as in the former case. The eye was opened on the fourth 
day. The graft had apparently taken. It was re-dressed with atropine-iodoform ointment and vaseline lint and both eyes kept bandaged till the seventh day when the stitches were removed. At this time the graft looked nice and clear, the chamber had formed, the pupil was round, the iris free and the patient could count fingers. The subsequent history is given in the case report.

The left cornea was dealt with on August 25, 1934, subsequent to suitable operative re-formation of the anterior chamber. On

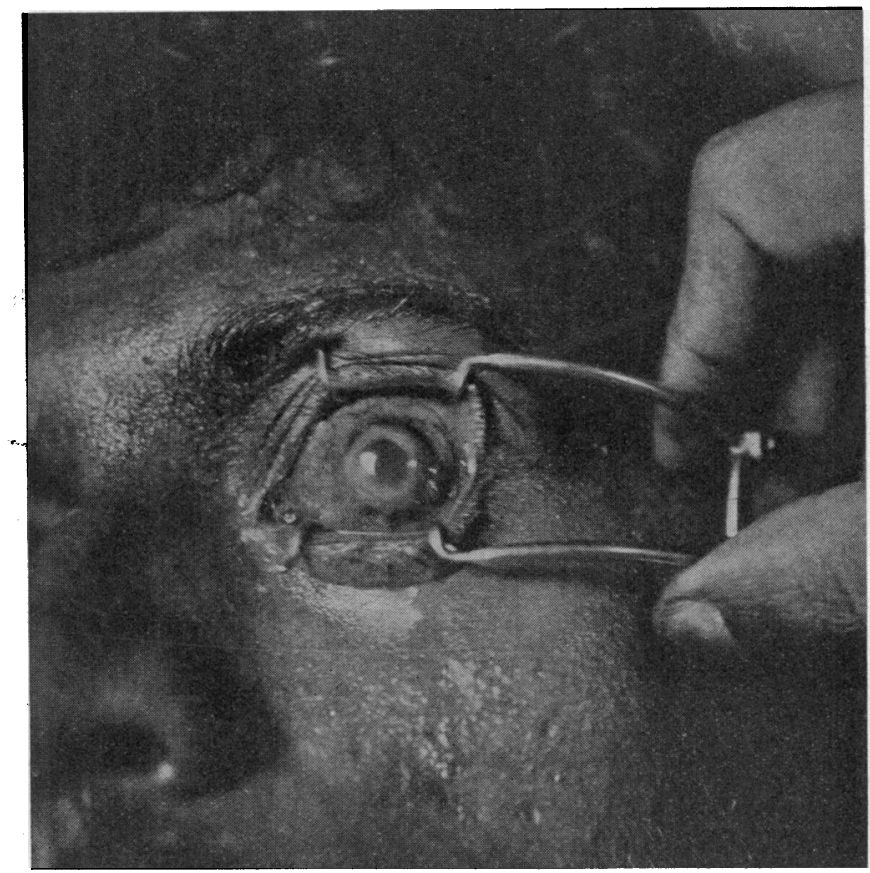

Photograph of a $9 \mathrm{~mm}$. graft on the 9th day.

this side it was determined to disregard the opinion of certain surgeons with regard to the unsuitability of cases with anterior synechiae. Our first aim was the reconditioning of the anterior chamber. This is a recognized procedure in this clinic and is one of our common operative methods. It consists in making a small keratome incision ( $2 \mathrm{~mm}$. inside length) and sweeping a suitable spatula over the synechiae. The spatula designed by Dr. Koman Nayar made locally is best for this purpose. (Messrs. Weiss have put a somewhat similar instrument on the market.) An iridectomy had to be performed owing to a prolapse following the freeing of synechiae. The grafting was carried out as in the right eye, there was practically no difference in technique except 
that on this occasion 9 and $8 \mathrm{~mm}$. trephines were used. With the larger discs it is obviously an advantage to have the disc larger than the hole. An aged blind glaucomatous donor was again utilized. Eleven days after the operation the graft was transparent, the chamber formed and clear, the fundus easily seen and the visual acuity 6/60 with correction. There was soon what we considered to be a recrudescence of his ocular syphilis, and deposits formed on the endothelium. Intensive treatment was employed as indicated in the case notes. The eye gradually quieted down, but left him with relatively poor vision, a great improvement, however, on his previous state.

In the right eye the cornea around the graft which had been very opaque gradually cleared, in the way noted by Elschnig in cases of interstitial keratitis, until eventually the extreme periphery became clearer in parts than the graft.

Case 1.

Hindu, female, aged 30 years, admitted August 26, 1933, trachoma with pannus both eyes, ulcer left eye; perforated, treated for trachoma.

September 30, 1933. Trachoma improved, ulcer healing but fistulous, Descemetocele left eye middle of lower quadrant; vision, counts fingers at a foot.

October 2, 1933. Corneal graft from a glaucomatous blind eye.

October 5, 1933. Eye dressed, stitches in position, chamber formed, graft taking.

October 9, 1933. Graft has taken, chamber full, stitches removed, graft relatively clear.

October 11, 1933. Small grey opacity in centre of graft, considerable vascularizat on from every quarter to the centre, junction red with new vessels, graft itself relatively clear, line of demarcation with cornea opaque and pink, anterior chamber full.

October 13, 1933. Central area of opacity larger, looks like necrosis starting in centre, the whole cornea is more opaque, pannus generalized.

October 20, 1933. Centre of graft clearer, yellow infiltration at the junction of graft and cornea on the nasal side.

October 27, 1933. Vascularization of the graft increasing; vision, fingers at 0.5 nietre.

December 12, 1933 . Webster's operation for commencing entropion, upper lid.

January 24, 1934. A point of iris adhering to the graft junction below.

January 30, 1934. Adhesion broken down through small limbal keratome incision.

February 5, 1934. Anterior synechia free, chamber full, graft clearing from periphery, some iris pigment on endothelium below.

May 11, 1934. Graft looks translucent on retro-illumination, but many fine vessels reaching in from periphery-opalescent to naked eye slightly more so than cornea ahcve which has cleared with treatment. Cannot estimate vision through graft on this account. It has formed an integral part of cornea more opaque than that above, more translucent than that below.

\section{Case 2. Right eye.}

Hindu, male, aged 28 years, admitted April 1, 1934, dense corneal leucomata both eyes, clearer at extreme periphery; vision, hand movements; projection good in all directions. Corneal microscope examination (limbal illumination), anterior chamber about normal depth, pupil roundish, active. Patient cannot get about alone.

April 7, 1934. Corneal grafting performed right eye, a $4 \mathrm{~mm}$. central disc removed and $5 \mathrm{~mm}$. eccentric graft inserted.

April 10, 1934. Eye dressed, graft in position, junction vascularized, graft clear, chamber formed-apparently "a take," atropine ointment and iodoform.

April 13, 1934. Dressing removed, stitches intact, graft in position, fairly clear, pupil round, chamber formed, stitches removed, atropine ointment and iodoform, patient able to count fingers. 
April 21, 1934. Corneal microscope examination : Pupil round-half dilated, vessels growing into graft from the junction; back of graft appears to have a greyish infiltration or deposit at the periphery-clear in centre. The graft appears swollen; atropine thrice daily, neosalvarsan 0.3 gram intravenously, and 1 c.c. hypoloid bismuth intramuscularly three days later.

April 26, 1934. Neosalvarsan 0.45 intravenously.

April 28, 1934. Corneal microscope : A fine yellowish-grey deposit all over back of graft. In front of this, graft still clear, a denser nodular infiltration towards " 3 o'clock" with invasion of brush-like vessels. Right eye vision, fingers at one foot: Continue neosalvarsan and bismuth.

May 23, 1934. Folds of Descemet's membrane, yellowish-grey deposits on endothelium, anterior to this, graft clear at centre, but invaded by fine vessels and haze at periphery.

Up to now has had six injections of arsenic and six of bismuth. Vision, fingers at one foot. Can make out shape of individuals and gets about the hospital.

June 23, 1934. Graft still shows endothelial deposit and peripheral haze, counts fingers at one foot, surface of graft smooth and continuous with general curve of cornea. Allowed to go home for a time prior to having the other eye grafted.

\section{Left eye.}

Returned July 9, 1934. Vision, hand movements, with limbal illumination. Corneal microscope reveals anterior synechiae, chamber shallow, irregular in depth, shape of pupil not determined, had two injections of neosalvarsan each $0.45 \mathrm{grm}$. and $1 \mathrm{c.c}$. of hypoloid bismuth $(0.2 \mathrm{grm}$. metal) in next 12 days.

July 21, 1934. Anterior synechiae freed through keratome incision in superior temporal quadrant, by our usual technique using Nayar's spatula.

July 22, 1934. - Iris prolapsed, prolapse excised, atropine and yellow oxide.

July 28, 1934. Eye quiet.

August 1, 1934. Corneal microscope retro-illumination: Chamber full, coloboma clear, released eye, continued atropine, put on Donovan's solution and potassium iodide.

August 16, 1934. Stopped Donovan's solution.

August 17, 1934. Neosalvarsan 0.45 gram.

August 20, 1934. Hypoloid bismuth 1 cc.

August 24, 1934. Neosalvarsan 0..5 gram.

August 25, 1934. Grafted. On this occasion 8 and $9 \mathrm{~mm}$. trephines were used, the graft taken from blind glaucomatous patient.

August 29, 1934. Graft in position.

August 31, 1934. Stitches removed, graft clear, pupil half dilated, round, pillars of coloboma free, anterior chamber normal depth.

September 3, 1934. Left eye vision, fingers at 3 metres. With ophthalmoscope, corneal refraction somewhat irregular, disc vertically oval, fundus normal, graft quite clear to naked eye; with the corneal microscope the graft is clear and its edges sharp and opaque except in the inferior nasal quadrant where there is a slight haze and trace of blood in the section. There are pigment deposits on the anterior lens capsule in the coloboma. Photograph taken of graft. Eye left free in Kirkpatrick's goggles.

September 5, 1931. Left eye vision, with -0.5 D. $\mathrm{sph} .=6 / 60$.

September 6, 1934. Eye irritable, fine deposits on endothelium, leeches. 0.45 neosalvarsan.

September 7, 1934. Much watering, iritic pain. Hot compresses, atropine, deep cyanide of mercury $(5 \mathrm{~m}$. of $1 / 4,000)$, sodii salicyl $1 \mathrm{gr}$. per pound body weight, blue pill gr. 4, followed by mag. sulph.

September 9, 1934. Eye quieter, faint haze advancing over 2/3rd of graft, starting from the inferior nasal quadrant. Milk injection 5 c.c., sub-conjunctival saline.

September 10, 1934. Milk injection 5 c.c., leeches. Uniform haze of graft. Hypoloid bismuth 1 c.c.

September 12, 1934. Milk injection 10 c.c. Two-thirds of graft becoming opaque, sub-conjunctival saline, intravenous injection of citrated malarial blood. (Had good rigors 17th, 18th, 19th, 20th, 21st, 22nd, 23rd-stopped the malaria 24th.)

September 13, 1934. Hot compresses, leeches. Haze of graft throughout, denser inferior nasal quadrant.

September 15, 1934. Graft clearing in superior temporal quadrant. 
September 17, 1934. Sub-conjunctival saline, atropine, dionine.

September 17 to September 24, 1934. In bed with malaria.

October 7, 1934. Started bismuth and arsenic injections again, dionine, atropine locally, and yellow oxide.

October 24, 1934. Eye quiet; right eye vision, fingers at 6 inches; left eye vision. fingers at one foot. Continue arsenic and bismuth, atropine, dionine, yellow oxide and massage, with sub-conjunctival salines.

November 8, 1934. Corneal microscope : Some cloudy opacity on the endothelium, and vessels invading the graft in its nasal half, no vessels temporal side. The opacification has taken place in the posterior part of graft, the substantia is clear. Continue dionine and yellow oxide, arsenic and bismuth.

December 12, 1934. During the past month, in addition to deposits on the endothelium and a deep haze, the epithelium developed several bullae, these subsided with massage, dionine and irrigation.

Present vision : Right eye, fingers at two feet; left eye, 1/60. Tension normal each eye, eyes quiet.

I do not imagine it is very much more difficult to get a large corneal graft to take in an eye uncomplicated by trachoma or congenital syphilis, i.e., an avascular eye, than in the above types of case, although, of course, the leucoma of congenital syphilis is the ideal soil to work on, for the fairly obvious reason that capillary proliferation up to the junction can and does take place rapidly. To obtain a high percentage of uniformly translucent large grafts is probably a thing of the future, but to give a patient previously blind and unable to get about, enough vision to walk about without aid, does not appear to present any peculiar difficulty. Successful corneal grafting to the extent indicated ought to be within the powers of any ophthalmic surgeon experienced in plastic methods. There is no difficulty about it, nor does it appear to require either the elaboration of technique or the preliminary practice on animals, indicated in an annotation in the Brit. Med. Jl. of May 26, 1934. It is not nearly such a difficult procedure as a Wheeler's whole lower lid Wolfe graft. In the latter the maintenance of uniform pressure over a thin flimsy skin graft on an elastic bed is a work of art which few can acquire. In corneal grafting, uniform pressure-the secret of successful grafting - tends to be maintained by the lid pressure against the fluid intraocular bed, without elaborate aids from the surgeon. The large grafts referred to above were cut with trephines selected from a nest of ordinary steel cylinders. Since then Messrs. Down Brothers have placed on the market, at my suggestion, a more elaborate nest of trephines. The needle holder made for me by Weiss for corneal suture work is well adapted for use with the Barraquer needles.

I must thank my colleague, Dr. K. Koman Nayar, for his suggestions and advice in the elaboration of details and help in the performance of various modifications of corneal plastic surgery, and Dr. V. Narayanaswami Pillai for his post-operative care of patients and their general treatment.

I must confess to failure so far in what has been another 
important modification-namely, the excision of complete or partial nipple-shaped corneal staphylomata and their substitution by large or complete corneal grafts. Since I described what is perhaps the best method of dealing with corneal staphylomata (Arch. of Ophthal., 1925, Vol. III, No. 2), I have been anxious to develop a better optical procedure in such cases. I feel sure that successful excision of complete corneal staphylomata-selected with regard to the condition of the posterior segment-and their replacement by clear or translucent cornea is only a matter of time. Our ideas on the subject are much more defined and our experience much greater than when the article referred to was written.

While preparing this note for publication, the Amer. Jl. of Ophthal. for October came to hand with an article by Castroviejo which shows that there are various means of accomplishing corneal grafting, but that the best has not yet been evolved. In the same journal the consulting editor discusses professional publicity. This coincidence, even if unintentional, prompts me to say that it is a pity that corneal grafting in England should have received such a vast amount of notice in the daily and popular pictorial lay press in the past year. I gather that the lay press in other parts of the world blindly followed suit. The press in India was no exception and agents seeking news on this subject had to be dealt with rather drastically.

\section{ANNOTATIONS}

\section{Blindness in Hereditary Ocular Disease}

In the third of the Dr. Elizabeth Matthai lectures, 1933-34 (Madras University), Lt.-Col. R. E. Wright enumerates a number of hereditary ocular diseases which he claims are preventible if parenthood is abstained from by the affected individuals and by those relatives who, although unaffected themselves, are liable to transmit hereditary disease in some instances.

The publication in these lectures of Wright's observations and ideas on this difficult subject comes at a time when considerable interest is being centred around the means of preventing blindness. The problem of sterilization of the subjects of hereditary ocular diseases has recently been raised by Myles Bickerton in the columns of the Brit. Med. Jl., 1934. It is not surprising that, in a matter of such national and social importance as this, disputes have arisen between persons whose enthusiasm to attempt the absolute elimination of this group of diseases is in conflict with others who, also failing to hold views that savour of scientific balance, pass to the other extreme and complacently 